\title{
BRALNI OKUS SLOVENCEV IN NJEGOVE POSLEDICE
}

\section{UVOD}

Zdi se, da smo zadnje čase zasuti s knjižno ponudbo. V supermarketih, trafikah, na poštah, celo na bencinskih servisih nas k nakupu vabijo prepolne knjižne police. Glede na tako ponudbo in glede na število izposoj v naših knjižnicah lahko sklepamo, da Slovenci relativno dosti beremo. A samo dejstvo, da beremo, še ne pomeni, da beremo kvalitetno.

\section{POMEN BRANJA}

Dejstvo je, da je branje izrednega pomena. Tudi tega, da knjige vplivajo na človekovo razmišljanje in mišljenje, se zavedajo že od nekdaj. Tako knjige v preteklosti niso bile dostopne vsakomur, knjige $z$ ideološko sporno vsebino so sežigali in prepovedovali, bile so podvržene številnim cenzuram itd. Še posebej pomembno je branje leposlovja, o čemer so bile - sploh v zadnjem času - narejene številne raziskave in analize. Pri nas se s pomenom in učinki branja najbolj poglobljeno verjetno ukvarja Meta Grosman, ki našteva naslednje možne učinke in funkcije branja $^{1}$ :

a. Ko beremo leposlovno delo, beremo o izkušnjah drugih ljudi, kar nam omogoča splošno zavedanje o možnih človekovih izkušnjah, njihovih razsežnostih in posledicah. Ko beremo, hkrati tudi spoznavamo metode pripovedovanja, ki jih kasneje lahko pri ubesedovanju lastnih izkušenj uporabimo tudi sami. Ravno slednjemu, torej ubesedovanju lastnih izkušenj, zadnje čase pripisujejo vse večji pomen, saj ljudem omogoča neke vrste »samoanalizo« oz. osmišljanje lastne življenjske izkušnje. Nekateri drugi avtorji (npr. Lesser) vidijo branje kot iskanje »samega sebe«, saj leposlovje ponuja obilico osebnostnih tem in izkušenj, s katerimi se lahko bralec poistoveti oz. identificira. ${ }^{2}$ Vez med literaturo in identiteto (poistovetenjem) ${ }^{3}$ je $\mathrm{v}$ zadnjem času vse bolj aktual-

\footnotetext{
Povzemam po Grosman (1998: 12 -13) in Grosman (1989: 27 - 40).

O tem piše Marko Juvan (2003, 3 - 18).

»Identiteta je [...] dvojna konstrukcija: narativno-interpretativna graditev 'sebstva', tj. istosti subjekta $v$ toku njegovih variacij in menjav, ter opredeljevanje takšnega subjekta z njegovo udeleženostjo/članstvom v eni ali več družbeno-kulturnih skupinah, razredih, kategorijah. Prek takšnih konstrukcij člani skupine dojemajo in opredeljujejo sami sebe, tako nanje gledajo tudi tisti, ki pripadajo drugačnim identitetnim konstrukcijam.«(Juvan, 2003: 12)
} 
na. A pomemben faktor ni le oblikovanje identitete bralca. Iskanje identitete, kriza identitete, razvoj identitete literarnih likov so stalne teme književnih del. Na oblikovanje literarnega dela pomembno vpliva tudi identiteta pisca. Juvan (2003: 13) navaja primer Franceta Prešerna, ki je v Vrbi razcepljen med nezadovoljivo moderno urbanostjo in izgubljeno tradicionalno vaškostjo, rodovnostjo.

b. Pomembno je tudi spoznanje o pomenu pripovedi za t. i. pripovedno spoznavanje, ki je »eden izmed dveh načinov spoznavanja delovanja in mišljenja, ki nam omogoča posebno obliko urejanja izkušnje, gledanja na svet in je nenadomestljivo. [...] Pripovedno spoznavanje ljudje uporabljajo za povezovanje različnih sestavin izkustva ali delovanja $v$ osmišljeno celoto. [...] Pripovedovanje / zamišljanje zgodbe je nujno potrebno za smiselno rekonstrukcijo preteklih dogodkov [...]. Omogoča nam tudi ustvarjalen razmislek o dejanskosti in (fantazijsko) zamišljanje še neobstoječega. (Grosman, 1998: 13)《

c. Spet drugi avtorji (npr. Harding) trdijo, da ima branje na bralca pomembnejši oz. večji vpliv kot njegove lastne življenjske izkušnje, saj je umetniško verodostojno oz. prepričljivo leposlovje dostikrat bolj osmišljeno, razumljivo in celovito. Pri tem je ključnega pomena bralec, ker bere brez lastne čustvene vpletenosti in brez predhodnih pričakovanj.

d. Ko govorimo o branju, nikakor ne moremo mimo jezika, ki je - kot sta dokazala Luckman in Berger ${ }^{4}$ - $»$ vistvu sredstvo, s katerim gradimo vse predstave o svetu in te predstave ohranjamo za sebe in poznejše generacije, v obliki starodavnih mitov, epske pripovedi, zgodovinske pripovedi in pripovedi sodobne znanosti. S pomočjo jezika tvorimo tudi osebno in narodno identiteto in vse medsebojne odnose ter predstavitve samega sebe, ki jih včasih imenujemo kar osebni imidž. (Grosman, 1998: 13) « Dejansko lahko samo z jezikom osmislimo svoje življenje in ves svet okoli sebe. Vsi stiki med živimi bitji potekajo preko jezi$\mathrm{ka}^{5}$. Leposlovje ima na voljo le jezik, a lahko $\mathrm{z}$ njim skorajda poljubno manipulira - ne le s posameznikom, temveč tudi s skupnostjo. Ugotovljeno je bilo tudi, da se že novorojenček pri prvih socialnih stikih uvaja v fiktivno rabo jezika. Z branjem leposlovja se še dodatno razvijajo fantazijske sposobnosti, ki pomembno vplivajo na razvoj bralne sposobnosti, analitičnega mišljenja, sposobnosti predvidevanja, kombinatornih sposobnosti in sposobnosti razumevanja sebe in sveta okoli sebe.

e. Posebno močan vpliv ima branje na otroka. Grosmanova (1989: 39) zagovarja tudi tezo, da branje kakovostnega mladinskega leposlovja omogoča otroku lažji vstop v njegovo kulturo in prispeva k uspešnosti socializacije. Omogoča mu tudi večjo možnost simboličnega izražanja in zapletenejših jezikovnih struktur, pozitivno pa vliva tudi na osebnostni razvoj otroka. Nudi mu možnost za razmišljanje o njegovi lastni izkušnji in ga navaja k izbiranju in odločanju o različnih možnostih.

4 Povzemam po Grosmanovi, ki citira Petra Bergerja (1967) The Sociology Construction of Reality: a Treatise in the Sociology of Knowledge.

5 Najsi bodi ustni ali pisni, lahko pa tudi znakovni ali katerikoli drugi način sporazumevanja. 


\section{TRIVIALNA LITERATURA}

Zgoraj sem omenila, da ima umetniško verodostojno oz. prepričljivo leposlovje pomemben vpliv na bralca. Je torej pomembno, ali beremo umetniško leposlovje ali kičasto leposlovje? Odgovor je vsekakor da. A najprej je treba definirati eno in drugo. Jasno mejo je vsekakor nemogoče potegniti, a splošno velja, da ima umetniško besedilo določene estetske značilnosti in vrednosti. Ob tem velja opomniti, da »sta estetska sodba in opis estetskih značilnosti veljavna le za bralce, ki jim je skupno določena zanimanje za književnost, horizont pričakovanj in običajno tudi določena ideologija." (Grosman, 1989: 31) Motiv za nastanek umetnostnega besedila je umetniško izražanje avtorjevega lastnega razmerja do sveta in njegovega lastnega videnja problema. Avtor takega besedila »pričakuje, da se bodo naslovniki strinjali z njim glede tega, da je izbrana izkušnja ali situacija zanimiva ali njegov odnos do nje primeren [...] (Grosman, 1989: 34) « Neumetniško besedilo ali kič6 je besedilo brez estetskih značilnosti in vrednosti. Hladnik (1983: 21) kot funkciji kiča oz trivialne literature navaja

- katarzično, kjer gre za zadovoljevanje potreb, predvsem po zabavi. Pomembni faktorji pri tem so radovednost, napetost in ljubezenska razsežnost;

- stimulativno, pri čemer gre za manipulativno vplivanje na obnašanje bralca. Tako naj bi preko kiča vladajoči razred manipuliral z množicami ${ }^{7}$.

Verjetno je ravno zadovoljevanje potrebe po zabavi oz. sprostitvi razlog, da je trivialna literatura (pri nas) tako popularna. Založbe, knjigarne in nenazadnje avtorji to dejstvo seveda s pridom izkoriščajo. T. i. poletno branje je, kot kaže, odličen vir zaslužka - kvaliteta samih del (in njihovih prevodov) ter dolgoročni učinki na bralci so najverjetneje drugotnega pomena.

\section{BRALNE STATISTIKE}

Zanimalo me je, koliko leposlovnih knjig se na mesec izposodi v slovenskih knjižnicah in koliko le-teh bi lahko uvrstili v okvir trivialne literature. Uporabila sem seznam stotih najbolje izposojanih knjig v vseh slovenskih knjižnicah, ki je dostopen na Cobissovi spletni strani; in sicer za junij, julij in avgust 2010. Junija se je na omenjenem seznamu znašlo 82 leposlovnih del $^{8}$, ki imajo skupaj več kot 68 tisoč izposoj. Julija je bilo neleposlovnih del le pet, leposlovje skupaj šteje kar okoli sto tisoč izposoj. Avgusta je zopet upadla izposoja leposlovnih del - na seznamu je 68 del s skupno le dobrimi dvanajst tisoč izposojami. Seveda si izposoditi ne po-

\footnotetext{
6 Izraz kič je povzet po Grosmanovi (1989), ki sicer uporablja tudi izraz literarna plaža (1998). S slednjim tovrstno literaturo označi tudi Kmecl (1995: 315). Miran Hladnik poleg že omenjenih (1983: 5 - 8) za to vrsto literature ponudi še izraze trivialna literatura, množična in zabavna literatura, šund ter popularna in poljudna literatura. Poudariti je potrebno, da pojmi niso popolnoma sopomenski; vsi razen izraza popularna literatura se nanašajo na estetsko razvrednoteno literaturo. Sama uporabljam izraz trivialna literatura. 7 Leposlovje ima močan vpliv na posameznikovo zavest in podzavest: preko kiča lahko vsekakor vplivamo na posameznikovo razumevanje sveta in njegovo mišljenje. Zlorabljajo ga lahko tudi vladajoče garniture za prikrito promocijo.

Ostalo so učbeniki in priročniki.
} 
meni še nujno knjigo tudi prebrati, a če vseeno sklepamo, da se večina teh knjig prebere, potem je zelo zaskrbljujoče, da je verjetno le roman Gorana Vojnovića Čefurji, raus! - glede na vse pohvale in prejete nagrade - lahko zanesljivo izločen s seznama trivialne literature ${ }^{9}$. Naj kot zanimivost omenim tudi, da je na listi desetih najbolje prodajanih knjig v slovenskih knjigarnah za april $2010^{10}$ vsaj pet del tovrstne literature ${ }^{11}$.

Na vrhu seznama s Cobissa je vse tri mesece Kathleen Woodiwiss ${ }^{12}$, ki se je z romanom Snubec proti svoji volji uvrstila celo na zgoraj omenjeni seznam najbolje prodajanih knjig. Zavzema vsa tri prva mesta vse tri mesece. Avtorica je tudi sicer izredno všeč našim bralcem, saj ima na seznamu še več svojih romanov; skupno ima krepko čez petnajst tisoč izposoj. Ljubezenski žanr trivialne literature je očitno (pri Slovencih) najbolj priljubljen, saj so na seznamu še številni drugi naslovi tega žanra. Slikajo različne ljubezenske zgodbe, za katere so značilni predvidljivi srečni konci in pričakovani zapleti, črno-belo slikanje likov (predvsem delitev na dober-slab), nagrajeni pozitivni liki in kaznovani slabi itd. Priljubljeni avtorji so tudi Danielle Steel, Julie Gerwood, Nicholas Sparks, Suzanne Enoch, Anita Shreve, Amanda Quick in številni drugi.

Naslednji je kriminalni roman. Še vedno prednjači Dan Brown s svojimi napetimi pustolovskimi romani Izgubljeni simbol, Da Vincijeva šifra, Angeli in demoni, Digitalna trdnjava. Tudi on je na seznamu najbolje prodajanih knjig, $\mathrm{v}$ knjižnicah ima skupno krepko preko deset tisoč izposoj. Letos je zelo bran tudi švedski avtor Stieg Larsson s svojo trilogijo Millenium. Za ta žanr so značilni predvsem vzdrževanje suspenza, nepričakovani preobrati, nezanesljivi liki (Kdo je $\mathrm{v}$ resnici pozitiven in kdo ne?) itd.

Zadnje čase izredno dobro brana so dela o vampirjih in ostala znanstvenofantastična literatura. Prednjačita Stephanie Meyer z romani iz zbirke Vampirska akademija in Robin Hobb z deli Morilčev vajenec in Kraljevi morilec. $V$ teh delih se pogosto pojavljajo fantazijski svetovi in liki, nadnaravne sile itd. Še vedno so zelo brana dela o Harry-ju Potterju avtorice J. K: Rowling.

Dokaj priljubljene so tudi knjige o življenjskih izkušnjah (trpinčenih) žensk; izstopajo dela o izkušnjah muslimank v Aziji in Afriki (npr. Prepovedana žena Verene Wermuth, Puščavska roža, Zbogom, Afrika in Bela Masajka Korinne Hoffman itd.). Slovence prevzema tudi zgodovinski žanr, ki opisuje zgodovinske dogodke in življenjepise zgodovinskih osebnosti, npr. Druga sestra Boleyn avtorice Philippe Gregory.

\section{NEGATIVNI UČINKI BRANJA TRIVIALNE LITERATURE}

Beremo torej kar precej, vendar premalo kvalitetne literature. $V$ šolah učitelji navajamo učence in dijake $\mathrm{k}$ branju kvalitetnejšega leposlovja in kritičnega mišlje-

Seveda se tudi znotraj okvira trivialne literature dela razlikujejo po kvaliteti.

10 Objavila ga je revija Bukla maja 2010.

11 Naj na tem mestu omenim še eno dejstvo, ki me je malce »zbodlo«: razen Vojnovića na seznamih praktično ni slovenskega leposlovja.

${ }_{12}$ Avgusta jo je prehitel le učbenik za fiziko. 
nja, ki je ključno tudi pri poznejšem samostojnem izbiranju branja. Da leposlovje $z$ določeno estetsko vrednostjo ne ponuja odgovorov in tem, ki jih mladi in starejši iščemo v delih, zagotovo ne drži. Starejši pubertetniki, ki radi berejo teme o spolnosti, smrti, grehu, predsodkih, padejo v t. i. bralni trans ob delih, kot so Salingerjev roman Varub mlade rži, V vrtincu avtorja Mitchella, Guest of the Nation (F. O'Connor) in A. Raudijevem romanu The Fountainhead ${ }^{13}$. Res je tudi, da jim vse te teme ponuja še marsikateri ljubezenski roman, npr. Neuničljiva K. Woodiwiss, a ob takih romanih si sploh mladi lahko ustvarjajo stereotipne predstave o svetu in nerealna pričakovanja, rešitve in življenjske (z)možnosti. Posledice pogostega ali izključnega branja trivialnih besedil so torej zelo kvarne in dolgoročne. Naslednji izmed slabih vplivov je tudi slabše razvita jezikovna zmožnost, saj so trivialna besedila pisana večinoma $v$ »lahkotnejšem «, nedvoumnem jeziku, ki ne pušča (veliko) možnosti za interpretacijo in lastno presojanje dogodkov; tudi metafore so stereotipne, banalne. Tak jezik seveda omogoča sproščujoče branje, saj ne zahteva prevelike miselne angažiranosti (česar se zelo dobro zavedajo tudi avtorji ${ }^{14}$ ), a s tem bralci izgubljajo zanimanje za zapletenejše ubeseditve in jezikovne možnosti (z leti mogoče tudi sposobnost za interpretacijo le-teh). Ti negativni učinki se pri otrocih še toliko bolj potencirajo. Otroci v literarnih delih namreč iščejo svoje vzornike in rešitve za svoje stiske in probleme ali si skušajo ustvariti predstavo o možnostih svojih prihodnjih vlog ali pa jih zanima predvsem to, kako drugi ljudje mislijo o takih in podobnih problemih (Grosman, 1989: 36). Vpliv literarnih vzornikov je tolikšen, da ga literatura izkorišča v vzgojne namene, medtem ko ga trivialna literatura dostikrat tudi zlorablja. Slednja vpliva tudi na (otrokovo) podzavest; zlasti kriminalni in znanstveno-fantastični žanri. Otroci tako zelo zgodaj berejo o truplih, forenzikih, neobstoječih svetovih itd. Zaradi že omenjenih ponavljajočih se stereotipov se seveda branja tako otroci kot odrasli lahko dokaj hitro naveličamo.

Naj se še enkrat vrnem k zgoraj omenjeni statistiki o izposoji knjig. Številčnost izposoje trivialne literature je glede na kvarne učinke, ki jih ima, res kar malce zaskrbljujoča. Vse te kvarne učinke (nekritično mišljenje, stereotipno tolmačenje in razumevanje sveta, slabe zmožnosti jezikovne interpretacije in rabe jezikovnih sredstev, sploh pa zavračanje branja in celo posmehljiv odnos do knjig) že vseskozi opažam pri svojih dijakih in mnogih odraslih. Dostikrat branje zavračajo, saj se jim zdi »brez zveze«, če lahko pogledajo film. Analize književnih del so za njih še večja izguba časa, saj pogosto mislijo, da od tega nič nimajo. Mogoče pa bi veljalo premisliti tudi o izbiri samih del, ki se jim največkrat zdijo dolgočasna, saj ne obravnavajo tem, ki jih zanimajo ${ }^{15}$. Če pa že berejo, po večini izberejo trivialno literaturo; po mojih izkušnjah največkrat znanstveno-fantastiko in detektivke. Odnosa do branja ponavadi ne spremenijo - po njem se ravnajo tudi kot odrasli in ga prenašajo na svoje otroke. In začaran krog je sklenjen.

\footnotetext{
Prim. še: Alenka Žagar: Srednješolske književne vsebine na recepcijskem situ.

14 Dokaz za to je raziskava Q. D. Leavis, ki je anketirala avtorje trivialne literature; le-ti so natančno navedli želje in pričakovanja svojih bralcev. Povzemam po Grosman (1989).

15 Prim. še: Alenka Žagar: Srednješolske književne vsebine na recepcijskem situ.
} 


\section{MOŽNI VZROKI ZA VELIKO PRILJUBLJENOST TRIVIALNE LITERATURE}

Zagotovo je ta negativen odnos do branja eden izmed vzrokov, da se tako množično zatekamo k trivialni literaturi. Mogoče pa si zaradi pomanjkljivega znanja književnosti in literarne teorije ter nizke zmožnosti kritičnega mišljenja ne znamo izbrati kvalitetnega leposlovja. Mogoče že kot otroci nismo bili vodeni k ustreznim izbiram.

Mogoče smo pa le preveliki konformisti in se nam $\mathrm{v}$ tem naglem svetu zdi škoda porabiti preveč časa za branje. Mogoče trivialno literaturo beremo tudi zato, ker jo zaradi preprostih jezika in zgodbe preberemo hitreje, ker ne zahtevata veliko razmišljanja. Zgodbi največkrat lahko sledimo tudi, ko delo »razkosamo« na več delov, med katerimi so tudi večji časovni premori.

Tako mnogokrat raje preberemo dve knjigi mimogrede, kot da bi se eni posvetili in si zanjo in za razmislek o njej vzeli čas. V sodobnem času pa si verjetno tudi dovolimo, da razni mediji na nas (pre)močno vplivajo. Sploh v tiskanih medijih se pojavlja veliko oglasov in opisov t. i. poletnega branja (tu se zopet neizbežno vrnemo k finančni plati založništva in pisateljevanja). Založbe same izdajajo razne zbornike žepnih knjig (med katerimi se, sicer v veliko manjšem številu, pojavljajo tudi avtorji, kot je Marquez ${ }^{16}$ ); precej strani jim namenja tudi revija Bukla. Revija je po mojem mnenju sicer kar dobro zasnovana, verjetno pa je njena največja »pomanjkljivost « to, da je brezplačna. Zato je poleg prispevkov priznanih strokovnjakov, kot sta npr. Manca Košir in Andrej E. Skubic, precej oglasov za - kajpa$\mathrm{da}$ - trivialno literaturo. Kljub temu prinaša relativno dobre intervjuje, portrete kvalitetnih pisateljev in pisateljic ter ocene (recenzije) posameznih del in njihovih prevodov. Književni listi, nov časopis Pogledi, televizijska oddaja Knjiga mene briga so še boljši. A se zopet poraja vprašanje: kdo jih bere oz. gleda? Verjetno precej ozek krog ljudi, ki se pomena kvalitetnega branja že tako ali tako zavedamo. Naj tu samo za primerjavo omenim še podatke o branosti časopisov ${ }^{17}$ : Delo je v imelo v letu 2009 naklado 134.000 izvodov, Večer 123.000 in Dnevnik 111.000, »rumena« Lady pa $224.000^{18}$.

\section{ZAKLJUČEK}

O vzrokih za branje trivialne literature in o posledicah le-tega bi se dalo (in moralo) razglabljati še mnogo dlje in mnogo več. Tu je osvetljenih le nekaj izhodišč za razmislek in mogoče celo za nadaljnje raziskovanje. Vsekakor se moram (na žalost) strinjati z Dragom Jančarjem, da je hitrost in cenenost izdajanja knjig velik problem.

\footnotetext{
16 V članku oglaševalske narave, objavljenem v junijski številki revije Bukla, Jana Jeseničnik imenuje kvalitetnejšo literaturo kot »najboljše«. Še en dokaz, da se tudi založniki še predobro zavedajo koliko (ne) kvalitetna je literatura, ki jo tiskajo in prevajajo.

17 Primerjava verjetno res ni najbolj realna; podatke navajam samo kot zanimivost o bralnem okusu Slovencev glede tiskanih medijev: očitno trivialno branje ne prevladuje le pri leposlovju.

18 Vir: spletna stran Dela.
} 


\section{BIBLIOGRAFIJA}

Delo. 26. oktober 2009. http://www.delo.si/clanek/97527

GROSMAN, Meta (1989) Bralec in književnost. Ljubljana: Državna založba Slovenije.

GROSMAN, Meta (1998) Zakaj je branje leposlovja pomembno za vsakogar. M. Grosman (ur.), Jezikovne zmožnosti za maturo. Ljubljana: Zavod Republike Slovenije za šolstvo, 12-16.

HLADNIK, Miran (1983) Trivialna literatura. Ljubljana: Državna založba Slovenije.

JESENIČNIK, Jana (2010) Poletno branje v knjigarnah Mladinske knjige. Bukla 6 / 54, 14.

JUVAN, Marko (2003) Stil in identiteta. Jezik in slovstvo 48, 3-18.

LEILER, Ženja (2010) Si naš ali njihov, rdeč ali črn, levi ali desni. Vmes pa nič. Intervju z Dragom Jančarjem. Pogledi I / 12, 8-10.

ŽBOGAR, Alenka (2003) Srednješolske književne vsebine na recepcijskem situ. Jezik in slovstvo 48, 3-18.

\section{POVZETEK}

\section{Bralni okus slovencev in njegove posledice}

Članek najprej navaja pomene in pozitivne učinke branja: boljše razumevanje lastne izkušnje, razvoj jezikovnih zmožnosti itd. Nadalje se osredotoča na trivialno literaturo: najprej jo definira, nato povzame statistične podatke o izposoji le-te v slovenskih knjižnicah v poletnih mesecih v letu 2010. Opiše tudi kvarne učinke branja tovrstnega leposlovja, še posebej na otroke, ki jih avtorica opaža tudi pri svojih dijakih: lažne (stereotipne) predstave o svetu, manjše zmožnosti kritičnega mišljenja in slabše poznavanje jezikovnih sredstev, vpliv na podzavest in zgledovanje po neprimernih literarnih junakih. Nadalje avtorica špekulira o možnih vzrokih za tovrstno izbiro branja.

Ključne besede: branje, pomen branja, trivialna literatura, vpliv trivialne literature, bralne statistike

\section{ABSTRACT}

Firstly, the importance and positive impacts of reading are listed: better comprehension of personal experience, development of linguistic skills etc. Further on, the article focuses on trivial literature: its definition and statistical data of borrowings in Slovene libraries in summer months 2010. Negative influences of reading trivial literature, especially on children, are enumerated. Most of them are noticed in the author's classes: stereotypic image of the world, poorer capabilities of critical thought and knowledge of linguistic means; also impact on subconscious, and following the example of inappropriate literary characters. At the end, the author speculates on possible reasons for such a reading choice. 
Keywords: reading, the importance of reading, trivial literature, impact of trivial literature, reading statistics 